\title{
Partially purified Asiasari radix inhibits melanogenesis through extracellular signal-regulated kinase signaling in B16F10 cells
}

\author{
JI-YEON JANG ${ }^{1}$, JUN-HYUK LEE ${ }^{2}$, HWA-KYOUNG SHIN ${ }^{1}$, \\ YUNG-HYUN CHOI ${ }^{3,5}$, JAE-DONG LEE ${ }^{4}$ and BYUNG-TAE CHOI ${ }^{1,5}$ \\ ${ }^{1}$ Division of Meridian and Structural Medicine, School of Korean Medicine, Pusan National University, \\ Yangsan 626-770; ${ }^{2}$ Chemistry and Biotechnology Examination Bureau, Korean Intellectual Property Office, \\ Daejeon 302-701; ${ }^{3}$ Department of Biochemistry, College of Oriental Medicine, Dongeui University, \\ Busan 614-710; ${ }^{4}$ Department of Microbiology, College of Natural Sciences, Pusan National University, \\ Busan 609-735, Korea; ${ }^{5}$ Blue-Bio Industry Regional Innovation Center, \\ Dongeui University, Busan 614-052, Korea
}

Received September 7, 2009; Accepted October 29, 2009

DOI: 10.3892/ijmm_00000343

\begin{abstract}
The active fraction of the extract of Asiasari radix, the $60 \%$ methanol chromatographic fraction from the ethyl acetate layer (PPAR), was used to investigate the melanogenesis signal pathway in B16F10 melanoma cells. PPAR led to significantly decreased melanin synthesis and tyrosinase activity in a dose-dependent manner. PPAR also reduced the expression of melanogenesis-related proteins including microphthalmia-associated transcription factor (MITF), tyrosinase, and tyrosinase-related protein (TRP)s while down-regulating the expression of mRNA of MITF and tyrosinase. Melanogenesis-regulating signals, such as mitogen-activated protein kinase (MEK)/extracellular signalregulated kinase (ERK), phosphatidylinositol 3-kinase (PI3K)/Akt and p38 mitogen-activated protein kinase (MAPK) were evaluated, and ERK was activated by PPAR. The selective inhibitor of MEK/ERK, PD98059, abrogated all suppressive activities of PPAR on melanin biosynthesis, tyrosinase activation and expression of melanogenesis-related proteins. These results suggest that ERK activation by PPAR contributes to reduced melanin synthesis via ERK signal pathway-mediated suppression of MITF and its downstream signal pathway.
\end{abstract}

Correspondence to: Dr Byung Tae Choi, Division of Meridian and Structural Medicine, School of Korean Medicine, Pusan National University, Yangsan 626-770, Korea

E-mail: choibt@pusan.ac.kr

Dr Jae Dong Lee, Department of Microbiology, College of Natural Sciences, Pusan National University, Busan 609-735, Korea E-mail: leejd@pusan.ac.kr

Key words: Asiasari radix, melanogenesis, micropthalmia-associated transcription factor, tyrosinase, extracellular signal-regulated kinase

\section{Introduction}

Melanogenesis is a multistage process that involves a cascade of enzymatic reactions regulated by tyrosinase and tyrosinaserelated protein (TRP)s $(1,2)$. Tyrosinase is a key enzyme that catalyses the hydroxylation of L-tyrosine to 3,4-dihydroxyphenylalanine (DOPA) and the subsequent oxidation of DOPA into dopaquinine (3). The intracellular concentration of cAMP plays a critical role in melanogenesis through activation of protein kinase A (PKA) and cAMP response element binding protein (CREB) transcription factor and promotes an increase in the expression of microphthalamia-associated transcription factor (MITF). MITF plays an important role as a transcriptional activator of genes that encode melanogenesis-related proteins such as tyrosinase and TRPs $(4,5)$.

It has been reported that activation of the extracellular signal regulated kinase (ERK) and phosphatidylinositol 3-kinase (PI3K)/Akt pathways induces hypopigmentation, suggesting that these signaling pathways regulate melanogenesis via MITF degradation or inhibition (6-8). Conversely, p38 mitogenactivated protein kinase (MAPK) has been implicated in melanogenesis via up-regulation of tyrosinase expression in B16F10 cells (9). Recent studies have focused on the specific mechanisms involved in melanogenesis to develop new therapeutic agents for skin pigmentation. The results of these studies have shown that inhibition of melanogenesis may control tyrosinase upstream signaling pathways such as a ERK, PI3K/Akt and p38 MAPK.

Asiasari radix has long been used in traditional Korean medicine to treat headaches, neuralgia, chronic bronchitis, asthma and allergies, as well as for its anti-bacterial effects. However, the extract of $A$. radix was found to significantly suppress melanin biosynthesis in our preliminary examinations, which indicated that some of its active ingredients influenced the signaling pathways involved in melanogenesis. In this study, we investigated the effects of partial purification from A. radix (PPAR) on the inhibition of melanin synthesis, including melanogenesis-related signaling pathways, in B16F10 cells. 


\section{Materials and methods}

Preparation of PPAR. Dry powdered roots of Asiasarum sieboldii $(300 \mathrm{~g})$ were immersed in 81 of distilled water and boiled under reflux for $150 \mathrm{~min}$. The resulting extract was then centrifuged $\left(2,000 \mathrm{x} \mathrm{g}\right.$ for $20 \mathrm{~min}$ at $\left.4^{\circ} \mathrm{C}\right)$ and filtered through a $0.2 \mu \mathrm{m}$ filter. The filtrate was then evaporated to dryness under reduced pressure. Next, the dried extract (102.3 g) was dissolved in water and further partitioned in succession with ethyl acetate (2 1 x 5), n-butanol, and distilled water, which produced fractions of $21.6,41.2$, and $37.1 \mathrm{~g}$, respectively. The ethyl acetate fraction was concentrated by rotary vacuum evaporation (Eyela, Tokyo, Japan). The $2.0 \mathrm{~g}$ residue was then subjected to octadesylsilane (ODS) open column chromatography using a 50x183 mm YMC-GEL (Kyoto, Japan) and eluted with the following, incrementally increasing solvent system: $100 \%$ distilled water, 20, 40, 60, 80, 100\% methanol $(\mathrm{MeOH}), 100 \%$ dichloromethane. Seven fractions were obtained, concentrated under reduced pressure, and freezedried. The active $60 \% \mathrm{MeOH}$ fraction $(109.2 \mathrm{mg}$ ) was used as the PPAR and a voucher specimen (WC34-2-4) and deposited at the School of Korean Medicine, Pusan National University.

Materials. 3,4-dihydroxyphenylalanine (L-DOPA), Melanin, PD98059 and B-actin antibody were purchased from Sigma (St. Louis MO, USA). A monoclonal antibody to MITF was purchased from Millipore (Bedford, MA, USA). Tyrosinase (C-19), TRP1 (G-17), dopachrome tautomerase (Dct, D-18), phospho-MEK (pMEK, Ser218/Ser222), MEK (12-B), phospho-ERK1/2 (pERK1/2, E-4), ERK1/2 (K-23), phosphoAkt (pAkt, Ser473), Akt (C-20), phospho-p38 (pp38, D-8) and p38 (H-147) were obtained from Santa Cruz Biotechnology (Santa Cruz, CA, USA). Antibodies recognizing phosphoCREB (pCREB, Ser133,1B6) and CREB (48H2) were obtained from Cell Signaling Technology (Danver, MA, USA). All other reagents used in this study were of the highest quality available.

Cell culture. B16F10 mouse melanoma cells (CRL 6323) were obtained from the American Type Culture Collection (Manassas, VA, USA). Cells were maintained in Dulbecco's modified Eagle's medium (DMEM, Gibco Life Technologies, France) with $10 \%$ fetal calf serum and $1 \%$ penicillin/streptomycin in a $5 \% \mathrm{CO}_{2}$ humidified incubator at $37^{\circ} \mathrm{C}$.

MTT assay. The general viability of the cultured cells was determined through the reduction of 3-(4,5-dimethylthiazol2-yl)-2,5-diphenyl-tetrazolium bromide (MTT) to formazan as described previously (10). After treating the PPAR, cells were incubated for $48 \mathrm{~h}$ at $37^{\circ} \mathrm{C}$ in an atmosphere containing $5 \%$ $\mathrm{CO}_{2}$. MTT ( $1 \mathrm{mg} / \mathrm{ml}$ in PBS) was then added to each well at $1 / 10$ volume of media. Cells were incubated at $37^{\circ} \mathrm{C}$ for $3 \mathrm{~h}$, and DMSO was to dissolve the formazan crystals. The absorbance at $570 \mathrm{~nm}$ was measured using a spectrophotometer (Spectra MAX 190, Molecular Devices, Sunnyvale, CA, USA).

Determination of the melanin content. The melanin content was measured using a slight modification of the method described by Tsuboi et al (11). Briefly, cells were washed with $\mathrm{PBS}$ and then dissolved in $1 \mathrm{~N} \mathrm{NaOH}$ in $10 \% \mathrm{DMSO}$ at $80^{\circ} \mathrm{C}$ for $1 \mathrm{~h}$. The absorbance was then measured at $475 \mathrm{~nm}$,

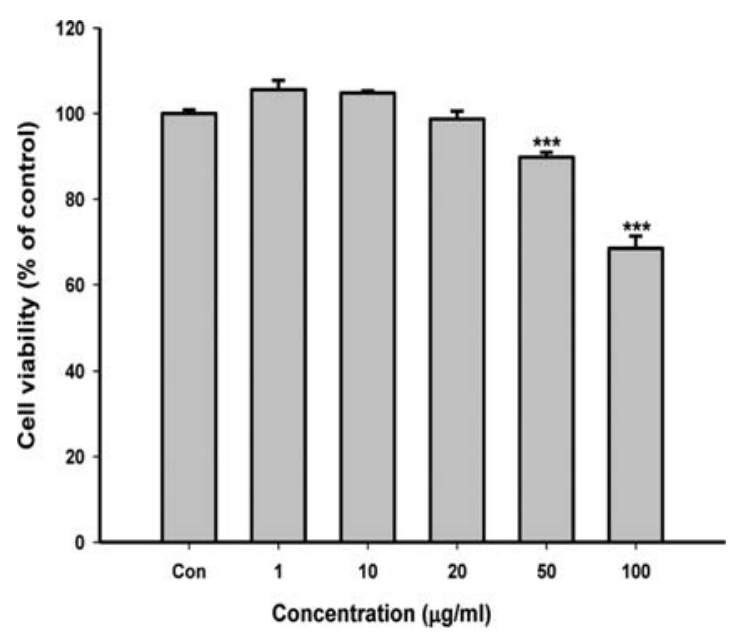

Figure 1. Effect of PPAR on B16F10 cell viability. Cells were treated with various concentrations of PPAR for $48 \mathrm{~h}$. Cell viability was determined by an MTT assay. Each percentage value in treated cells was calculated with respect to that in control cells. Data expressed as the means \pm SEM of three independent experiments carried out in triplicate. ${ }^{*} \mathrm{P}<0.05,{ }^{* *} \mathrm{P}<0.01,{ }^{* * *} \mathrm{P}<0.001$ vs control.

with standard melanin being used to quantify the melanin content and expressed as a percentage of the control.

Measurement of tyrosinase activity. The tyrosinase activity was measured based on its dopa oxidase activity using a slight modification of the method reported by Tomita et al (12). Briefly, cells were lysed by incubation at $37^{\circ} \mathrm{C}$ for $30 \mathrm{~min}$ in RIPA buffer $(0.1 \mathrm{M}$ sodium phosphate, $\mathrm{pH} 7.0,1 \%$ Triton $\mathrm{X}-100,0.1 \mathrm{mM}$ PMSF, $1 \mathrm{mM} \mathrm{NaF}$ ). Lysates were then centrifuged at $10,000 \mathrm{x}$ g for $20 \mathrm{~min}$ to obtain the supernatant as the crude tyrosinase extract for the activity assay. The reaction mixture contained $0.1 \mathrm{M}$ sodium phosphate $(\mathrm{pH} 7.0$ ), $0.05 \% \mathrm{~L}-\mathrm{DOPA}$ and the supernatant (tyrosinase source). After incubation at $37^{\circ} \mathrm{C}$ for $1 \mathrm{~h}$, the dopachrome was monitored by measuring the absorbance at $405 \mathrm{~nm}$ in a microplate reader.

Reverse transcription-polymerase chain reaction (RT-PCR). Total RNA was prepared from B16F10 melanoma cells using Trizol reagent ${ }^{\mathrm{TM}}$ (Invitrogen, Paisley, UK) according to the manufacturer's protocols. cDNA was synthesized using $2 \mu \mathrm{g}$ of total RNA and oligo $\mathrm{dT}_{\mathrm{d}(18)}$ primer with taq polymerase (Promega) in a $20-\mu 1$ reaction system. Reverse transcription was conducted by incubating the mixture at $37^{\circ} \mathrm{C}$ for $45 \mathrm{~min}$ and then termination at $95^{\circ} \mathrm{C}$ for $5 \mathrm{~min}$. The following primers were used, 5'-CCCGTCTCTGGAAACTTGATCG-3' (forward), and 5'-CTGTACTCTGAGCAGCAGGTG-3' (reverse) for MITF; 5'-GAGAAGCGAGTCTTGATTAG-3' (forward) and 5'-TGG TGCTTCATGCGCAAAATC-3 (reverse) for tyrosinase; 5'-ATGAGAAGGAGATCACTGC-3' (forward) and 5'CTG CGCAAGTTAGGTTTTGT-3' (reverse) for B-actin. PCR was conducted by subjecting the reaction mixture to 30 cycles of $30 \mathrm{sec}$ at $94^{\circ} \mathrm{C}, 30 \mathrm{sec}$ at $55^{\circ} \mathrm{C}$, and $60 \mathrm{sec}$ at $72^{\circ} \mathrm{C}$. The PCR products were then electrophoresed on $1.5 \%$ agarose gels and stained with ethidium bromide. All data were normalized to ß-actin primers.

Western blot analysis. Cells were cultured and then harvested using RIPA buffer A containing $20 \mathrm{mM}$ Tris- $\mathrm{HCl}$, pH 8.0, 
A
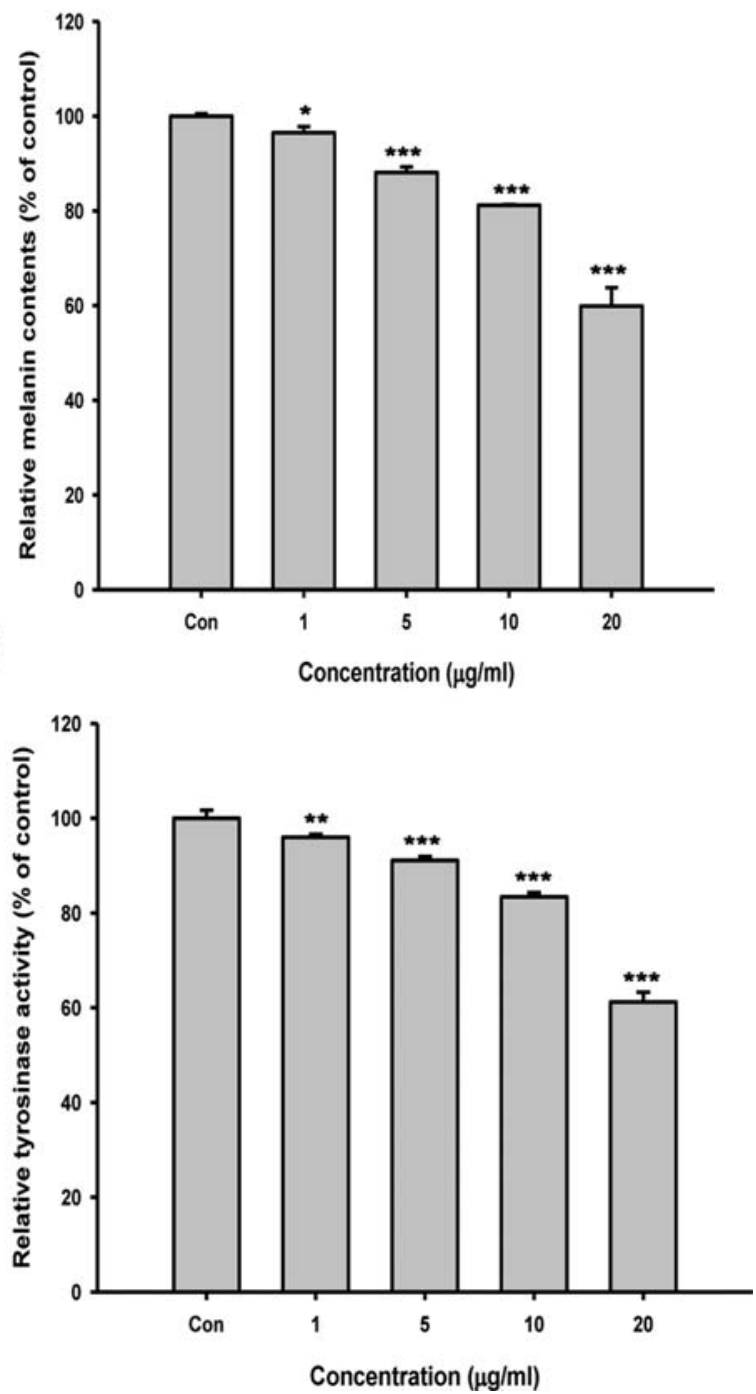

Figure 2. Effect of PPAR on cellular melanin synthesis (A) and tyrosinase activity (B) in B16F10 cells. Cells were treated with $1-20 \mu \mathrm{g} / \mathrm{ml}$ of PPAR. Each percentage value for treated cells was reported relative to that of control cells. The results shown are the means \pm SEM and representative of three independent experiments. ${ }^{*} \mathrm{P}<0.05,{ }^{* *} \mathrm{P}<0.01,{ }^{* * *} \mathrm{P}<0.001$ versus control.

$150 \mathrm{mM} \mathrm{NaCl}, 1 \%$ NP-40, 2 mM EDTA, 1 mM PMSF, $10 \mathrm{mM}$ $\mathrm{NaF}, 1 \mathrm{mM} \mathrm{Na} \mathrm{VO}_{4}$ and protease inhibitors (Sigma). The protein concentrations were then determined by a Bradford assay (BioRad, Richmond, CA, USA), after which $30 \mu \mathrm{g}$ of protein were separated by electrophoresis on a $10 \%$ SDSpolyacrylamide gel and then transferred to a nitrocellulose membrane (Whatman, Germany). The membrane was blocked with 5\% skim milk and incubated with MITF (1:200), tyrosinase (1:250), TRP1 (1:250), Dct $(1: 250)$, anti-pMEK $(1: 1,000)$, anti-MEK $(1: 1,000)$, anti-pERK1/2 $(1: 1,000)$, anti-ERK1/2 $(1: 1,000)$, anti-pAkt $(1: 1,000)$, anti-Akt $(1: 1,000)$, antipp38MAPK $(1: 1,000)$, anti-p38 MAPK $(1: 1,000)$, anti-pCREB $(1: 1,000)$ or anti-CREB $(1: 1,000)$. All bands were visualized using horseradish peroxidase-conjugated secondary antibodies (1:2,000, Santa Cruz Biotech, CA, USA) using an enhanced chemiluminescence system (Pierce Biotech, Rockford, IL, USA). The results of the Western blotting assays reported here are representative of at least three experiments.
A
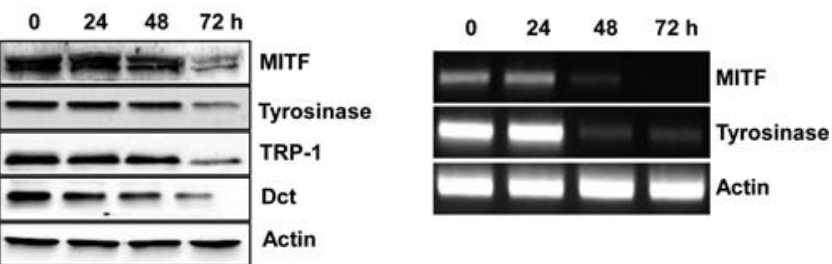

Figure 3. Time-course effect of PPAR on the expression of melanogenesisrelated proteins in B16F10 cells. Cells were treated with $20 \mu \mathrm{g} / \mathrm{ml}$ of PPAR for the indicated times. (A) Western blotting assays were conducted to evaluate the expression levels of MITF, tyrosinase, TRP1, Dct and B-actin on the same blot. (B) Representative RT-PCR results of MITF, tyrosinase mRNA expression. Average mRNA expression as normalized with B-actin.

Statistical analysis. All data were expressed as the mean \pm SEM. The means, standard errors, and Student's t-test were determined using SigmaPlot (San Jose, CA, USA). A P-value $<0.05$ was considered to indicate statistical significance.

\section{Results}

Effects of PPAR on melanin biosynthesis and tyrosinase activity. Initially, we investigated the cytotoxic effects of PPAR in cells treated with $1-100 \mu \mathrm{g} / \mathrm{ml}$ of the extract. PPAR showed no cytotoxic effect on B16F10 cells at a concentration of $0-20 \mu \mathrm{g} / \mathrm{ml}$ (Fig. 1). To determine the effects of PPAR on melanin synthesis and tyrosinase activity, cells were exposed to concentrations ranging from $0-20 \mu \mathrm{g} / \mathrm{ml}$. As shown in Fig. 2, the cellular melanin content and tyrosinase activity decreased significantly in response to treatment with PPAR and this decrease occurred in a dose-dependent fashion. These findings suggest that PPAR regulates tyrosinase activity and subsequently inhibits melanin synthesis in B16F10 cells.

Effect of PPAR on the expression of melanogenic proteins and $m R N A$. To investigate the effect of PPAR on melanogenesisrelated proteins, B16F10 cells were treated with $20 \mu \mathrm{g} / \mathrm{ml}$ of PPAR for 24, 48 and $72 \mathrm{~h}$. As shown in Fig. 3A, the expression of melanogenic proteins showed time-dependent downregulation in response to treatment with PPAR. The effects of PPAR on the level of MITF and tyrosinase mRNA expression were also evaluated. The results revealed that the mRNA levels of MITF and tyrosinase decreased significantly in a timedependent manner in response to PPAR (Fig. 3B). These findings indicate that the inhibitory activity of PPAR does not directly suppress the activity of tyrosinase as much as it regulates the tyrosinase upstream signaling pathway related to its activation and expression.

Effect of PPAR on melanogenesis-related signaling pathways. Activation of the ERK, PI3K/Akt and p38 MAPK pathways was involved in the regulation of melanogenesis. Therefore, we examined PPAR to determine if it influenced the MEK/ERK, PI3K/Akt and p38 MAPK signaling pathways with transcription factor CREB. As shown in Fig. 4, PPAR significantly upregulated activation of ERK1/2 from early time points in B16F10 cells. However, PPAR did not activate PI3K/Akt or p38. These results suggest that the suppressive mechanism of PPAR on 
$\begin{array}{llllllll}0 & 2 & 15 & 30 & 60 & 180 & 360 & \mathrm{~min}\end{array}$

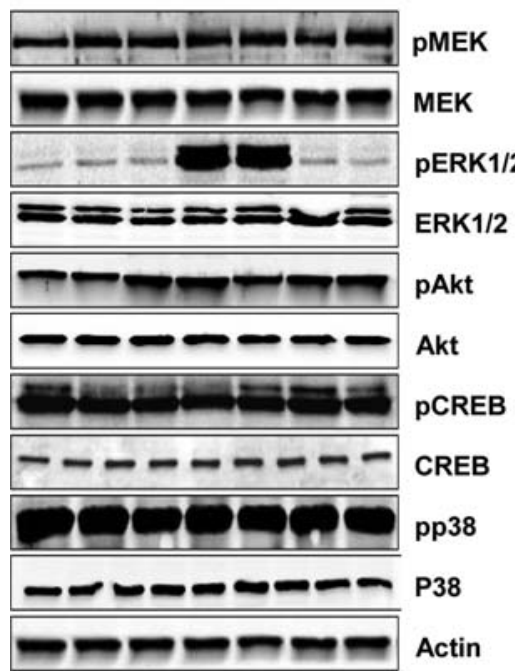

Figure 4. Effect of PPAR on the expression of melanogenesis-related proteins in B16F10 cells. After $24 \mathrm{~h}$ of starvation, B16F10 cells were treated with $20 \mu \mathrm{g} / \mathrm{ml}$ PPAR for the indicated times. Western blotting assays were used to examine the phosphorylation of MEK, ERK1/2, Akt, CREB and p38 MAPK. Equal protein loading was confirmed by $ß$-actin expression. melanogenesis is involved in activation of the ERK signaling pathway.

Effect of PD98059 on the suppressive mechanism of PPAR. Because PPAR activates the phosphorylation of ERK, we examined PD98059, a selective inhibitor of MEK/ERK, to determine if it inhibited the suppressive activity of PPAR on melanogenesis. As shown in Fig. 5A and B, the melanin synthesis and tyrosinase activity in cells co-treated with PPAR and PD98059 was higher than in cells treated with PPAR alone. PD98059 abrogated PPAR-induced MITF down-expression and partially recovered tyrosinase, TRP1 and Dct expression (Fig. 5C). These results suggest that ERK activation mediated by PPAR contributes to reduced melanin synthesis via MITF and its downstream signal pathway.

\section{Discussion}

A. radix, which primarily originates from Asiasarum sieboldii or Asiasarum heterotropoides, has long been used for the treatment of various pains and inflammatory disorders of the
A

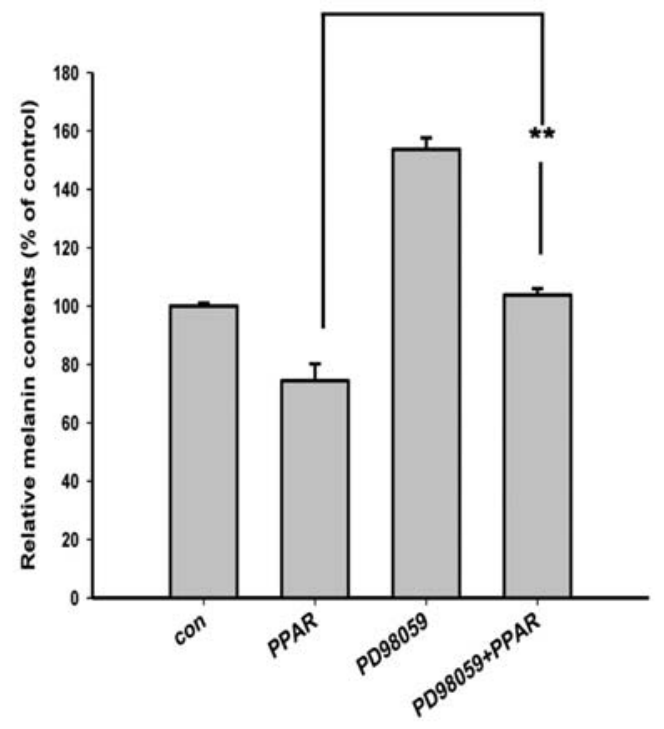

B

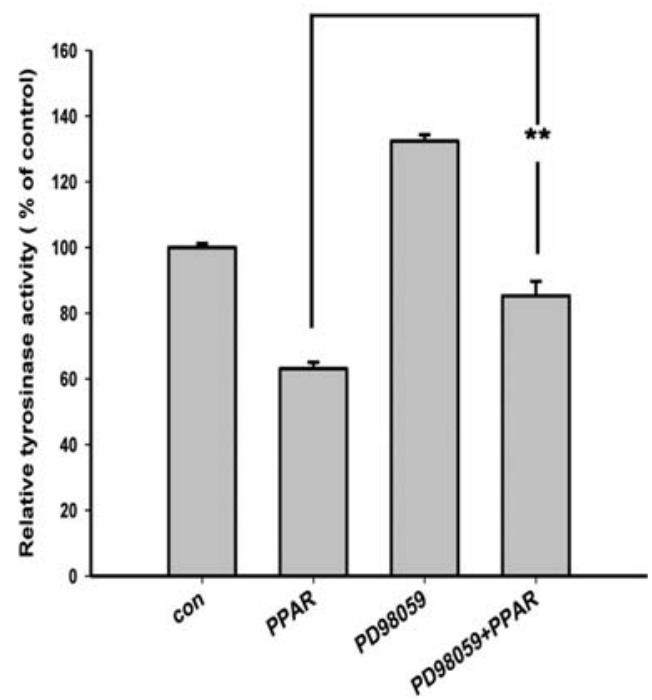

C

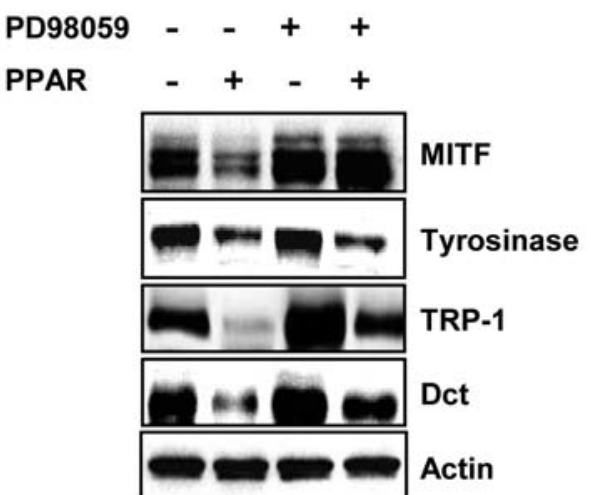

Figure 5. Effect of PD98059 pretreatment on cellular melanin synthesis (A) and tyrosinase activity (B) in B16F10 cells. B16F10 cells were pretreated in the absence (-) or presence (+) of $20 \mu \mathrm{M}$ of PD98059 for $1 \mathrm{~h}$ followed by incubation with $20 \mu \mathrm{g} / \mathrm{ml}$ of PPAR. The results shown are the means \pm SEM and representative of three independent experiments. ${ }^{* *} \mathrm{P}<0.01$ versus control. (C) $\mathrm{B} 16 \mathrm{~F} 10$ cells were pretreated in the absence $(-)$ or presence $(+)$ of $20 \mu \mathrm{M}$ PD98059 for $1 \mathrm{~h}$, after which the cells were treated with or without $20 \mu \mathrm{g} / \mathrm{ml}$ of PPAR. Proteins were extracted and subjected to Western blotting assays and the expression levels of MITF, tyrosinase, TRP1 and Dct and B-actin were determined on the same blot. 
respiratory tract in traditional Korean medicine. Accordingly, considerable effort has been directed towards evaluating the various biological activities of $A$. radix, particularly its antinociception and memory enhancing effects $(13,14)$. The extract of $A$. radix enhances memory via activation of ERK1/2 in the rat hippocampus (14), which suggests that $A$. Radix contains active ingredients that would be useful for regulation of melanogenesis-related signal pathways, including inhibition of MITF-tyrosinase signaling and/or activation of MEK/ERK, PI3K/Akt and p38 MAPK signaling.

Therefore, in this study, bioassay-guided purification was conducted by determining the inhibitory effect of $A$. radix on melanin synthesis and tyrosinase activation in B16F10 cells. The ethyl acetate layer was concentrated and the residual aqueous suspension and subjected to ODS open column chromatography with aqueous $\mathrm{MeOH}$ followed by dichloromethane. The results revealed that the melanogenesis-inhibitory activity was concentrated in the $60 \% \mathrm{MeOH}$ fraction (fraction four).

Partial purification was then used to investigate the effects of this extract on melanogenesis in B16F10 cells. We found that decreased melanin synthesis and tyrosinase activity was accompanied by reduced MITF, tyrosinase and TRPs expression (Figs. 2 and 3). Therefore, we evaluated MITF and tyrosinase mRNA expression to determine if PPAR had an effect on the MITF transcription level. The results revealed that MITF and tyrosinase mRNA decreased in a time-dependent fashion in PPAR-treated cells (Fig. 3B).

These results indicate that the suppressive activity of PPAR on melanogenesis is not due to the direct down-regulation of tyrosinase activity. The suppressive activity of PPAR on melanogenesis is linked to down-regulation of MITF-tyrosinase expression signaling pathways. Transcriptional regulation of melanogenic proteins is primarily dependent on the expression of MITF, which is a master transcriptional regulator of key melanogenic enzymes.

Recently, several reports have indicated that the activation of ERK and PI3K/Akt signaling reduced melanin synthesis through MITF degradation and inhibition, respectively. Activation of ERK by c-kit stimulation phosphorylates MITF at serine 73, and the phosphorylated MITF is followed by MITF ubiquitination and degradation (15-17). Activation of the PI3K/Akt signaling pathway has also been implicated in the inhibition of melanogenesis $(18,19)$. The inhibition of PI3K/Akt signaling plays a key role in the phosphorylation of MITF on serine 298, which leads to stimulation of tyrosinase expression (8).

Conversely, it is well known that the p38 MAPK cascade is involved in melanogenesis in B16 melanoma cells. The activation of p38 MAPK up-regulates MITF expression and promotes the transcription of tyrosinase (20). CREB is a MITF transcription factor that is involved in the melanogenic signaling pathway through phosphorylation. Phosphorylated CREB interacts with CREB binding protein (CBP) to activate the expression of MITF, which results in the indirect activation of tyrosinase promoter by MITF (21).

Therefore, we investigated PPAR to determine whether it activates the MEK/ERK, PI3K/Akt and p38 MAPK pathways with CREB in B16 melanoma cells. As shown Fig. 4, we found that PPAR only induced activation of the ERK pathway from the early time points, and it did not activate the Akt or p38 MAPK pathways. To confirm the involvement of ERK signaling, we evaluated the effects of PD98059 as a selective MEK/ERK inhibitor on PPAR-induced down-regulated melanogenesis. The PPAR-reduced melanin synthesis was recovered by PD98059 via abrogation of PPAR-mediated MITF, tyrosinase and TRPs expression (Fig. 5).

Generally, our results show that ERK signaling was activated by PPAR and that the MITF and tyrosinase mRNA and protein levels were attenuated. Furthermore, treatment with a selective MEK/ERK inhibitor abrogated the PPARmediated activity of melanogenesis. These results suggest that ERK plays an important role in PPAR-mediated hypopigmentation through MITF and its downstream signal pathway, including tyrosinase and TRPs. The ERK activation induces MITF phosphorylation and degradation, which results in reduced tyrosinase expression and melanin synthesis (6). In the present study, phosphorylated CREB was slightly decreased at early time points and the transcriptional level of MITF was also reduced by PPAR. We propose that PPAR inhibits pigmentation by indirectly regulating tyrosinase via ERK activation and subsequent MITF down-regulation. However, there is a possibility that CREB activation by PPAR is partially controlled at the MITF transcriptional level with ERK-mediated MITF degradation.

\section{Acknowledgements}

This work was supported by the Technology Development Program for Agriculture and Forestry, Ministry of Agriculture and Forestry, Republic of Korea (106072-3) and by the BlueBio Industry Regional Innovation Center (RIC08-06-07) at Dongeui University as an RIC program under the Ministry of Knowledge Economy and the City of Busan.

\section{References}

1. Kobayashi T, Urabe K, Winder A, Jimenez-Cervantes C, Imokawa $\mathrm{G}$, Brewington $\mathrm{T}$, Solano $\mathrm{F}$, Garcia-Borron JC and Hearing VJ: Tyrosinase related protein 1(TRP1) function as a DHICA oxidase in melanin biosynthesis. EMBO 13: 5818-5825, 1994.

2. Yokoyama K, Suzki H, Yasumoto K, Tomita Y and Shibahara S: Molecular cloning and functional analysis of a cDNA coding for human DOPAchrome tautomerase/tyrosinase-related protein-2. Biochem Biophys Acta 1217: 317-321, 1994.

3. Hearing VJ and Tsukamoto K: Enzymatic control of pigmentation in mammals. FASEB J 5: 2902-2909, 1991.

4. Bertolotto C, Abbe P, Hemesath TJ, Bille K, Fisher DE, Ortonne JP and Ballotti R: Microphthalmia gene product as a signal transducer in cAMP-induced differentiation of melanocytes. J Cell Biol 142: 827-835, 1998.

5. Bertolotto C, Buscà R, Abbe P, Bille K, Aberdam E, Ortonne JP and Ballotti R: Different cis-acting elements are involved in the regulation of TRP1 and TRP2 promoter activities by cyclic AMP: pivotal role of M boxes (GTCATGTGCT) and of microphthalmia. Mol Cell Biol 18: 694-702, 1998.

6. Kim DS, Hwang ES, Lee JE, Kim SY, Kwon SB and Park KC: Sphingosine-1-phosphate decreases melanin synthesis via sustained ERK activation and subsequent MITF degradation. J Cell Sci 116: 1699-1706, 2003.

7. Kim DS, Kim SY, Chung JH, Kim KH, Eun HC and Park KC: Delayed ERK activation by ceramide reduces melanin synthesis in human melanocytes. Cell Signal 14: 779-785, 2002.

8. Lee J, Jung K, Kim YS and Park D: Diosgenin inhibits melanogenesis through the activation of phosphatidylinositol-3kinase pathway (PI3K) signaling. Life Sci 27: 249-254, 2007. 
9. Singh SK, Sarkar C, Mallick S, Saha B, Bera R and Bhadra R: Human placental lipid induces melanogenesis through p38 MAPK in B16F10 mouse melanoma. Pigment Cell Res 18: 113$121,2005$.

10. Kim EK, Kwon KB, Han MJ, Song MY, Lee JH, Lv N, Choi KB, Ryu DG, Kim KS, Park JW and Park BH: Inhibitory effect of Artemisia Capillaris extract on cytokine-induced nitric oxide formation and cytotoxicity of RINm5F cells. Int J Mol Med 19: 535-540, 2007.

11. Tsuboi T, Kondoh H, Hiratsuka J and Mishima Y: Enhanced melanogenesis induced by tyrosinase gene-transfer increases boron-uptake and killing effect of boron neutron capture therapy for amelanotic melanoma. Pigment Cell Res 11: 275282,1998 .

12. Tomita T, Maeda K and Togami H: Melanocyte-stimulating properties of arachidonic acid metabolites: possible role in postinflammatory pigmentation. Pigment Cell Res 5: 357-361, 1992.

13. Suzuki Y, Yuzurihara M, Hibino T, Yano S and Kase Y: Aqueous extract of Asiasari radix inhibits formalin-induced hyperalgesia via NMDA receptors. J Ethnopharmacol 123: 128-133, 2009.

14. Han Y and Kim SJ: Memory enhancing actions of Asiasari radix extract via activation of insulin receptor and extracellular signal regulated kinase (ERK) I/II in rat hippocampus. Brain Res 974: 193-201, 2003.
15. Wu M, Hemesath TJ, Takemoto CM, Horstman MA, Wells AG, Price ER, Fisher DZ and Fisher DE: c-kit trigger dual phosphorylations, which couple activation and degradation of the essential melanocyte factor Mi. Genes Dev 14: 301-312, 2000.

16. Hemesath TJ, Price ER, Takemoto C, Bagdalian T and Fisher DE: MAP kinase links the transcription factor Microphthalmia to c-kit signaling in melanoytes. Nature 391: 298-301, 1998.

17. Xu W, Gong L, Haddad MM, Bischof O, Campisi J, Yeh ET and Medrano EE: Regulation of Microphthalmia-associated transcription factor MITF protein levels by association with the ubiquitin-conjugation enzyme hUBC9. Exp Cell Res 255: $135-143,2000$

18. Khaled M, Larribere L, Bille K, Aberdam E, Ortonne JP, Balloti R and Bertolotto C: Glycogen synthase kinase 3beta is activated by cAMP and plays an active role in the regulation of melanogenesis. J Biol Chem 277: 33690-33697, 2002.

19. Kim DS, Kim SY, Moon SJ, Chung JH, Kim KH, Cho KH and Park KC: Ceramide inhibits cell proliferation through Akt/PKB inactivation and decreases melanin synthesis in Mel-Ab cells. Pigment Cell Res 14: 110-115, 2001.

20. Widlund HR and Fisher DE: Microphthalmia-associated transcription factor: a critical regulator of pigment cell development and survival. Oncogene 22: 3035-3041, 2003.

21. Park HY and Gilchrest BA: Signaling pathways mediating melanogenesis. Cell Mol Biol 45: 919-930, 1999. 